\title{
Enterovirus subtyping in a routine UK laboratory setting between 2013 and 2017
}

Hannah C. Howson-Wells, Stephen Winckles, Camille Aliker, Alexander W. Tarr, William L. Irving, Gemma Clark, and C. Patrick McClure*

*Corresponding author: patrick.mcclure@nottingham.ac.uk

Author affiliations: Clinical Microbiology, Nottingham University Hospitals NHS Trust, Nottingham, NG7 2UH (H.C. Howson-Wells, G. Clark, W.L. Irving), Life Sciences, University of Nottingham, Nottingham, NG7 2UH UK (S.Winckles, C.Aliker, A.W. Tarr, W.L. Irving, C.P. McClure) \& NIHR Nottingham Biomedical Research Centre, Nottingham University Hospitals NHS Trust and the University of Nottingham (A.W. Tarr, W.L. Irving, C.P. McClure).

\section{Abstract word count: 249}

Main article word count: 2629

\section{Keywords}

Enterovirus; VP1; genotyping; viral diagnostics; RT-PCR; reference laboratory 


\section{Abstract}

\section{Background}

Human enteroviruses ( $\mathrm{hEV}$ ) are the leading cause of viral meningitis. hEV genotyping is predominantly performed through amplification and sequencing of viral capsid protein-1 (VP1), frequently by national reference laboratories (NRLS).

\section{Objective}

To determine the frequency of genotyping failure in our NRL-submitted samples and apply a superior alternative assay to resolve untyped specimens.

\section{Study design}

We initially audited genotyping data received for a cohort of patients in the East Midlands, UK by the NRL between 2013 and 2017, then identified an alternative RT-PCR typing method by literature review and evaluated primers from both assays in silico against comprehensive publicly available genomic data. The alternative assay was further optimised and applied to archived nucleic acids from previously untypable samples.

\section{Results}

Genotyping data showed a significant increase in untypable hEV strains through the study period ( $p$ $<0.005$ ). Typing failure appeared unrelated to sample type or viral load. In silico analyses of 2,201 hEV genomes showed high levels of mismatch between reference assay primers and clinically significant hEV-species, in contrast to a selected alternative semi-nested RT-PCR VP1-typing assay. This alternative assay, with minor modifications, successfully genotyped 23 of 24 previously untypable yet viable archived specimens (EV-A, $n=4 ; E V-B, n=19)$. Phylogenetic analyses identified no predominant strain within NRL untypable isolates, suggesting sub-optimal reference assay sensitivity across hEV species, in agreement with in silico analyses.

\section{Conclusion}


This modified highly sensitive RT-PCR assay presents a suitable alternative to the current English national reference VP1-typing assay and is recommended in other settings experiencing typing failure. 


\section{Highlights}

- $32 \%$ of enteroviral samples referred to a national reference laboratory failed typing

- Regular re-evaluation of RT-PCR primers is required in enteroviral diagnostics

- Recommended WHO primers remain optimal for contemporary genomes, including EV-D68

- 23 of 24 (96\%) viable but 'untypable' samples were typed by this alternative assay

- Simple and effective in-house enteroviral typing could support national surveillance 


\section{Introduction}

2

Enteroviral infections in humans are caused by species A-D, commonly referred to as the human enteroviruses (EV). Transmission of EVs occurs via the faecal-oral or respiratory route through person-to-person contact (direct) or from contaminated environmental sources (indirect) [1-3]. The majority of EV infections (50-80\%) are asymptomatic or result in mild, self-limiting febrile or respiratory illnesses that do not require treatment [1]. However, EVs are responsible for a diverse range of clinical syndromes, from hand foot and mouth disease to acute haemorrhagic conjunctivitis, and site of infection and severity varies by species, serotype and host physiology.

Due to their inherent neurotropism, EVs are the leading cause of viral meningitis and meningoencephalitis in all age groups [1]. Young age, immunocompromise and diagnosis delay are documented risk factors for developing severe or fatal EV infection [4-6]. Therapeutic options for severe infections are limited, with sufficient evidence lacking to justify clinical use [7]. Symptom management is the mainstay of patient management, with fast implementation of appropriate infection prevention control (IPC) procedures the principle method of preventing and controlling nosocomial outbreaks [8].

Fast, accurate diagnostic assays and international EV surveillance are essential for identifying emerging virulent strains, monitoring shifts in serovar circulation and outbreak control [3, 8-10]. Reverse-transcription polymerase chain reaction (RT-PCR) assays, which target the highly conserved $5^{\prime}$ untranslated region (UTR) genomic region, are the new gold standard for EV diagnosis due to their superior sensitivity and turn-around time (TAT) compared to the previously favoured cell culture [3]. Routine RT-PCR targeting the 5' UTR has led to a rise in UK cases of EV being reported [11]. However, high levels of genetic conservation make the 5' UTR an unsuitable target for EV typing assays. EV type is ideally determined through amplification and alignment of variable regions within the VP1 gene [3]. It is well established that prevalent EV genotypes are constantly evolving both temporally and spatially [12] and typing assays must be robust enough to detect and characterise all EV 
subspecies to reflect this changing epidemiology. However, the effect of epidemiological changes on current genotyping methodologies remains unknown.

In our regional diagnostic laboratory EV detection is determined by a commercial 5' UTRbased assay, then positive predominantly neurological specimens are referred to the national reference laboratory (NRL) for confirmation and genotyping $[13,14]$. Due to an apparent increase in diagnostically untypable specimens, we conducted a four-year audit of submissions, evaluated both the current assay and an alternative recommended by the World Health Organisation (WHO, [8]), on all available complete genome sequences in silico, then applied the optimised alternative assay on available residual specimens previously determined as untypable.

\section{Materials and Methods}

\section{Specimens and ethics}

All positive EV investigations performed within NUH Clinical Microbiology from October $1^{\text {st }}$ 2013 to September $30^{\text {th }} 2017$ were included in this study. Samples were previously detected and quantified predominantly by the Fast Track Diagnostics viral meningitis multiplex assay, generating cycle threshold (cT) values and by the AusDiagnostics viral CSF multiplex generating copies per $10 \mu \mathrm{l}$ from September 2016 onward. Duplicate results were removed with neurological entries preferentially retained if multiple EV positive specimens were investigated per patient. In the event of duplicate specimens from the same anatomical site, the earliest total nucleic acid (TNA) extract with an available typing result was retained. Ethical approval for the use of residual material was provided under the Nottingham Health Science Biobank Research Tissue Bank, REC reference 15/NW/0685.

\section{cDNA Synthesis and Semi-Nested Polymerase Chain Reaction (snPCR)}

TNA extraction was performed on the bioMérieux ${ }^{\mathrm{TM}}$ NucliSENS• easyMAG• system [15]. and resulting TNA eluates $(50 \mu \mathrm{l})$ were stored at $-80^{\circ} \mathrm{C}$ long term. CDNA was synthesized in $20 \mu$ volumes using RNA to cDNA EcoDry ${ }^{\mathrm{TM}}$ Premix with Random Hexamers (Clontech Laboratories) as per 
manufacturer's instruction, except lyophilised RT mastermix was resuspended in $9 \mu$ LEPC-treated $\mathrm{H}_{2} \mathrm{O}$ before addition of $10 \mu \mathrm{l}$ TNA and $1 \mu \mathrm{l}$ of $1 \mathrm{pmol} / \mu \mathrm{l}$ enterovirus specific primers (AN32, AN33, AN34 and AN35, Table 1) $[16,17] .5 \mu \mathrm{l}$ cDNA was used in a modified version of the first round PCR (PCR1) as described by Nix and colleagues $[16,17]$. PCR1 comprised $1 \times$ HotStarTaq PCR buffer (QIAGEN), primers p224/p222 (Table 1) at 50 pmol, $400 \mu \mathrm{M}$ total dNTPs, $1.25 \mathrm{U}$ HotStarTaq DNA polymerase (QIAGEN) and molecular grade $\mathrm{H}_{2} \mathrm{O}$ in a $50 \mu \mathrm{l}$ volume, then thermocycled at $95^{\circ} \mathrm{C}(15$ min), followed by 40 cycles at $95^{\circ} \mathrm{C}$ for $30 \mathrm{sec}, 42^{\circ} \mathrm{C}$ for $30 \mathrm{sec}, 72^{\circ} \mathrm{C}$ for $2 \mathrm{~min}$, then $72^{\circ} \mathrm{C}$ for $2 \mathrm{~min}$. This PCR1 product $(1 \mu \mathrm{l})$ was used in a semi-nested (sn)PCR ( $25 \mu \mathrm{l}$ volume), as per PCR1 except with primers AN89/AN88 (10 pmol, Table 1), $0.625 \mathrm{U}$ of HotStarTaq DNA polymerase and 40 cycles at $95^{\circ} \mathrm{C}$ for $30 \mathrm{sec}, 60^{\circ} \mathrm{C}$ for $20 \mathrm{sec}, 72^{\circ} \mathrm{C}$ for $30 \mathrm{sec}$.

snPCR products were separated and visualised on a $2 \%$ agarose gel and ranged from $~ 350-$ 400 bp due to variation in VP1 gene lengths across serotypes, as previously described $[16,18]$. PCR reactions were repeated once if no PCR product resulted. If unsuccessful after repeat, cDNA was subjected to two quality control PCRs using primer pairs EQ1/EQ2 [19] and EQ2 with primer 91F targeting the $5^{\prime}$ UTR of the EV genome and generating $~ 150 \mathrm{bp}$ and $\sim 480 \mathrm{bp}$ fragments respectively. Reactions were performed in $15 \mu \mathrm{l} \mathrm{HotStarTaq} \mathrm{reactions} \mathrm{under} \mathrm{conditions} \mathrm{above} \mathrm{for} \mathrm{snPCR} \mathrm{with} 55^{\circ} \mathrm{C}$ annealing, 45 secs elongation time and 55 cycles total.

\begin{tabular}{|c|c|c|c|c|}
\hline Primer Name & Sequence $\left(5^{\prime}-3^{\prime}\right)$ & Gene & Location (nt) & Reference \\
\hline \multicolumn{5}{|c|}{ cDNA Synthesis } \\
\hline AN32 & GTYTGCCA & VP1 & $3009-3002$ & [16] \\
\hline AN33 & GAYTGCCA & VP1 & $3009-3002$ & [16] \\
\hline AN34 & CCRTCRTA & VP1 & $3111-3104$ & [16] \\
\hline AN35 & RCTYTGCCA & VP1 & $3010-3002$ & [16] \\
\hline \multicolumn{5}{|c|}{ First-step PCR (PCR1) } \\
\hline p224 & GCIATGYTIGGIACICAYRT & VP3 & $2207-2226$ & [16] \\
\hline p222 & CICCIGGIGGIAYRWACAT & VP1 & 2969-2951 & [16] \\
\hline \multicolumn{5}{|c|}{ Semi-nested PCR (snPCR) } \\
\hline AN89 & CCAGCACTGACAGCAGYNGARAYNGG & VP1 & $2603-2628$ & [16] \\
\hline AN88 & TACTGGACCACCTGGNGGNAYRWACAT & VP1 & $2977-2951$ & [16] \\
\hline \multicolumn{5}{|c|}{ cDNA Quality Control PCR (CDNA-QC-PCR) } \\
\hline EQ1 & ACATGGTGTGAAGAGTCTATTGAGCT & 5 NCR & $408-433$ & [19] \\
\hline EQ2 & CCAAAGTAGTCGGTTCCGC & $5^{\prime} \mathrm{NCR}$ & $549-531$ & [19] \\
\hline
\end{tabular}


Table 1: Primers used in the study. Sequence locations are relative to the PV1 Mahoney strain (GenBank accession number V01149), with ascending and descending coordinates indicating forward and reverse primers respectively.

Sequencing and Sequence Analysis

PCR products of expected size were diluted 1:10 in $\mathrm{H}_{2} \mathrm{O}$ and subject to Sanger sequencing (Source

BioScience) with primer AN88 (3.2 pmol, [16]). Sequence identity was assessed using NCBI Standard

Nucleotide BLAST (BLASTn) [20] and the Genome Detective enterovirus typing tool:

https://www.genomedetective.com/app/typingtool/etv/ [21]. Resulting sequences and metadata

were submitted to Genbank under accession numbers MT614252-MT614274.

Statistical Analyses

Significance values were calculated in IBM SPSS Statistics for Mac (version 24.0) and GraphPad Prism (version 8.3).

Results

\section{Audit of Local Enterovirus Typing Data}

A retrospective audit of all EV investigations performed at NUH Clinical Microbiology from October $1^{\text {st }} 2013$ to September $30^{\text {th }} 2017$ (inclusive, $n=41,088$ ) yielded $390 \mathrm{EV}$ positive results. After omission of duplicate patient results ( $n=69$, see supplementary file) 321 unique infective episodes were identified. These positive specimens principally included cerebrospinal fluid (CSF) $(41.74 \%)$, swabs (including skin) (24.92\%), and samples from the upper respiratory tract $(24.92 \%)$ and gastrointestinal tract (4.98\%).

EV typing at the NRL was requested for 138/321 positives (42.99\%, Figure 1, A), 47 of which (34.06\%) were deemed 'untypable' or no typing result was received. For samples passing NRL quality control (QC), no correlation between specimen type or EV viral load and an untypable result was observed (see supplementary file). When analysed by date, a 5-fold increase in untypable results 
95 strain frequency was significant $(p$ value $=0.0073)$ despite the declining number of specimen 96 referrals in 2016-17. 

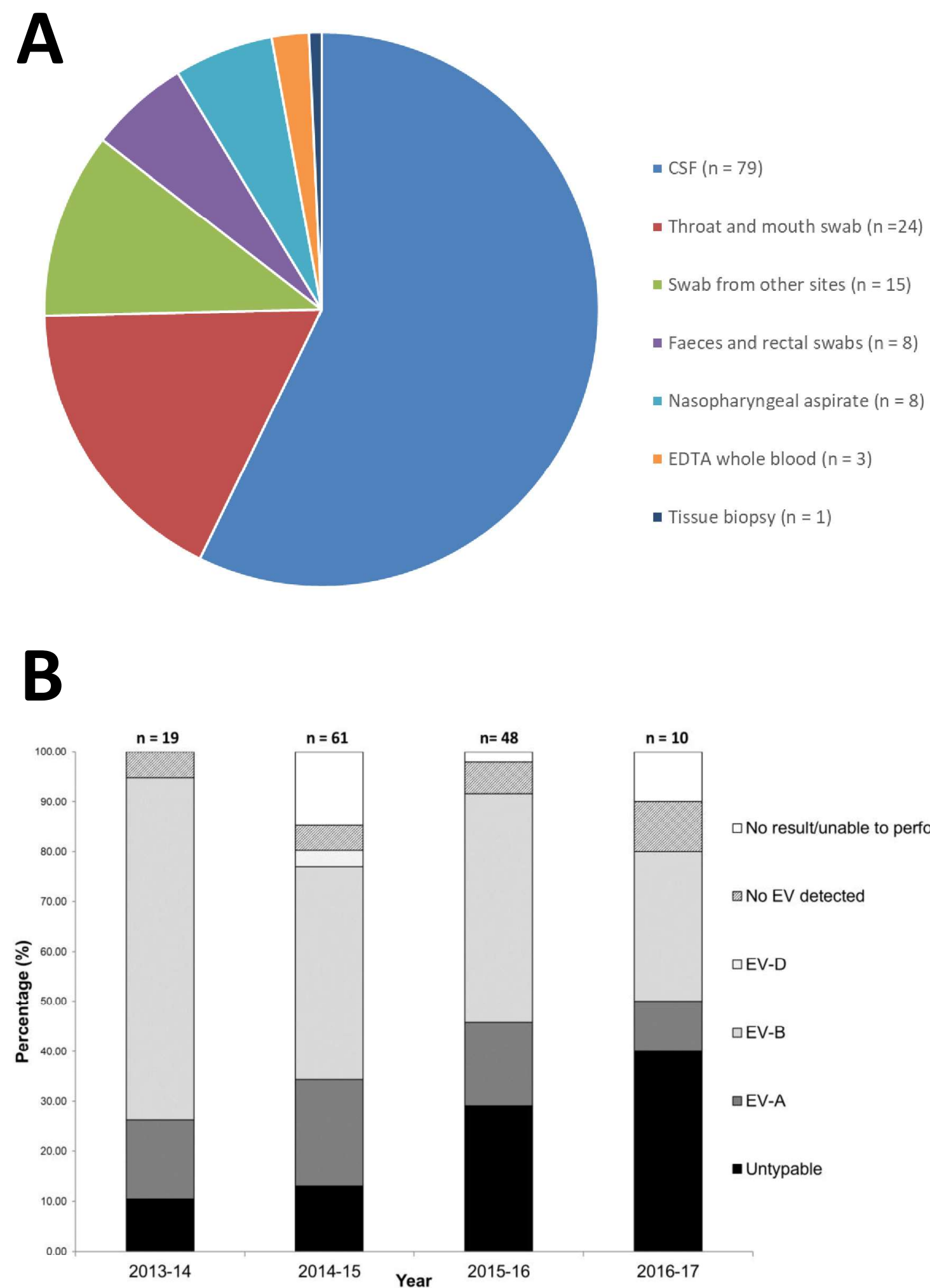

Figure 1: Breakdown of $138 \mathrm{EV}$ positive eluates submitted for genotyping by specimen type, detected in the four-year period between 2013-2017 (A) and EV typing data from the NRL, by species identified or outcome, over successive 12-month periods (from September $30^{\text {th }}$ inclusive) (B). Neurological specimens, cerebrospinal fluid; upper respiratory tract, nasopharyngeal aspirate, throat swabs and mouth swab; lower respiratory tract, tracheal aspirate; blood, EDTA; swabs from other sites include wound, skin and swabs from undefined sites. $n=$ number of positive EV specimens referred to the NRL for typing within each time period. 


\section{Re-screening of previously untypable enteroviruses}

Our literature review identified a RT-snPCR assay by Nix and colleagues [16] as the most widely adopted worldwide for the typing of EVs (see supplementary file). Our in silico analysis of primers from this publication [16] and the current NRL typing assay [13] was performed against 2,201 EV A-D complete genome sequences (see supplementary file). Primers designed by Nix and colleagues gave the greatest coverage: only one potentially significant $3^{\prime}$ terminal mismatch was observed in a single primer / strain combination, in contrast to $\geq 4$ mismatches in $50 \%$ of primer / strain combinations for the NRL assay (see supplementary file). This provided strong evidence that the pan-EV primers designed by Nix et al [16] still offer sufficient coverage of clinically relevant EV species and serotypes since their design 14 years ago. A modified Nix VP1 RT-snPCR protocol was therefore optimised on a panel of twelve EV positive TNA of known genotype (four EV-As, four EVBs, one EV-C and three EV-D, see supplementary file) and $100 \%$ concordance was observed with previous NRL typing.

The assay was then applied to the 28 available TNAs from the 47 samples that failed typing by the NRL, with successful amplification achieved in 23 instances (82.1\%), all of which were successfully sequenced and typed (Table 2). Of the five extracts that failed RT-snPCR, two (Samples 4 and 10) failed cDNA quality control (QC) PCR (cDNA-QC-PCR) [19] indicating failure of the RT step and likely degradation of extracted RNA. Two extracts (Samples 7 and 14 ) had $<10 \mu$ l of original extract available for analysis and cDNA was produced in half volume $(5 \mu \mathrm{l})$ which was insufficient for repeat after RT-snPCR failure. The final extract (Sample 11) failed RT-snPCR on repeat but passed both 5' UTR CDNA-QC-PCRs with sequencing of the extended 5' UTR PCR suggestive of EV-A species (Table 2).

Typing by phylogenetic analyses [21] showed broad distribution across EV-A and B species (Table 2). The majority of the 23 newly genotyped samples were EV-B $(n=19)$, with a predominance of echoviruses ( $n=14,73.7 \%)$ : types E9 $(n=3)$, E6 $(n=3)$ and E5 $(n=3)$ being the most common (Table 

of this species for causing viral meningitis [1]. In addition to multiple EV-B species, three A6 sequences (Table 2 ) were also observed and 137 collectively support reference laboratory typing failure by primer mismatch, rather than alternative 138 sporadic means. As samples were from deduplicated patient data, it is assumed they are separate 139 infective episodes and may be related to a local outbreak or cluster, however investigation of sample 140 clinical details was beyond the scope of this study. 


\begin{tabular}{|c|c|c|c|c|c|c|c|c|}
\hline \multirow{2}{*}{$\begin{array}{c}\text { Extract } \\
\text { Reference }\end{array}$} & \multirow{2}{*}{$\begin{array}{l}\text { Specimen Extract } \\
\text { Derived From }\end{array}$} & \multirow{2}{*}{$\begin{array}{l}\text { cT value (black) or EV } \\
\text { copies / } 10 \mu \mathrm{l} \text { (blue) }\end{array}$} & \multicolumn{2}{|c|}{ EV RNA Detected } & \multicolumn{2}{|c|}{ Typing Result by PCR } & \multicolumn{2}{|c|}{ Sequencing Result for $5^{\prime}$ UTR } \\
\hline & & & NRL & RT-snPCR & NRL & RT-snPCR & NRL & RT-snPCR \\
\hline Sample 1 & CSF & 33.28 & $\checkmark$ & $\checkmark$ & Untypable & E7 & $\begin{array}{c}\text { Suggestive of } \\
\text { EV-B }\end{array}$ & $\mathrm{n} / \mathrm{a}$ \\
\hline Sample 2 & CSF & 39.92 & $\checkmark$ & $\checkmark$ & $\begin{array}{c}\text { Untypable } \\
\text { (confirmed non D-68 strain) }\end{array}$ & E25 & $\mathrm{n} / \mathrm{a}$ & $\mathrm{n} / \mathrm{a}$ \\
\hline Sample 3 & CSF & 37.4 & $\checkmark$ & $\checkmark$ & (c) & E6 & $\mathrm{n} / \mathrm{a}$ & \\
\hline Sample 4 & NPA & 27.02 & $\checkmark$ & $x$ & Untypable & Untypable & $\begin{array}{l}\text { Suggestive of } \\
\text { EV-B }\end{array}$ & $\begin{array}{c}\text { RNA QC Fail } \\
\text { Unable to sequence }\end{array}$ \\
\hline Sample 5 & STHR & 20.39 & $\checkmark$ & $\checkmark$ & Untypable & E18 & $\begin{array}{l}\text { Suggestive of } \\
\text { EV-B }\end{array}$ & $\mathrm{n} / \mathrm{a}$ \\
\hline Sample 6 & CSF & 30.2 & $\checkmark$ & $\checkmark$ & Untypable & E9 & $\begin{array}{c}\text { Suggestive of } \\
\text { EV-B }\end{array}$ & $\mathrm{n} / \mathrm{a}$ \\
\hline Sample 7 & CSF & 33.0 & $\checkmark$ & $\checkmark$ & Untypable & Untypable & $\begin{array}{l}\text { Suggestive of } \\
\text { EV-B }\end{array}$ & $\begin{array}{l}\text { RNA QC Pass } \\
\text { Insufficient extract for } \\
\text { 5' UTR sequencing }\end{array}$ \\
\hline Sample 8 & Whole Blood & 36.19 & $\checkmark$ & $\checkmark$ & Untypable & E9 & $\mathrm{n} / \mathrm{a}$ & $\mathrm{n} / \mathrm{a}$ \\
\hline Sample 9 & STHR & 30.3 & $\checkmark$ & $\checkmark$ & Untypable & E9 & $\begin{array}{c}\text { Suggestive of } \\
\text { EV-B }\end{array}$ & $\mathrm{n} / \mathrm{a}$ \\
\hline Sample 10 & CSF & 38.0 & $x$ & $x$ & None & None & $\begin{array}{l}\text { No RNA } \\
\text { detected }\end{array}$ & $\begin{array}{c}\text { RNA QC Fail } \\
\text { Unable to sequence }\end{array}$ \\
\hline Sample 11 & STHR & 31.6 & $\checkmark$ & $\checkmark$ & Untypable & Untypable & $\mathrm{n} / \mathrm{a}$ & $\begin{array}{c}\text { RNA QC Pass } \\
\text { Suggestive of E-71 }\end{array}$ \\
\hline Sample 12 & CSF & 29.85 & $\checkmark$ & $\checkmark$ & Untypable & E6 & $\mathrm{n} / \mathrm{a}$ & $\mathrm{n} / \mathrm{a}$ \\
\hline Sample 13 & NPA & 17.7 & $\checkmark$ & $\checkmark$ & $\begin{array}{c}\text { Untypable } \\
\text { (confirmed non D-68 strain) }\end{array}$ & CVB1 & $\mathrm{n} / \mathrm{a}$ & $\mathrm{n} / \mathrm{a}$ \\
\hline Sample 14 & CSF & Unavailable & $\checkmark$ & $\checkmark$ & $\begin{array}{c}\text { Untypable } \\
\text { (confirmed non D-68 strain) }\end{array}$ & Untypable & $\mathrm{n} / \mathrm{a}$ & $\begin{array}{c}\text { RNA QC Pass } \\
\text { Insufficient extract for } \\
\text { 5' UTR sequencing }\end{array}$ \\
\hline Sample 15 & CSF & 33 & $\checkmark$ & $\checkmark$ & Untypable & E6 & $n / a$ & $\mathrm{n} / \mathrm{a}$ \\
\hline Sample 16 & STHR & 22.3 & $\checkmark$ & $\checkmark$ & Untypable & CVA6 & $\mathrm{n} / \mathrm{a}$ & $\mathrm{n} / \mathrm{a}$ \\
\hline Sample 17 & $\mathrm{CSF}$ & 33.63 & $\checkmark$ & $\checkmark$ & Untypable & CVB5 & $\mathrm{n} / \mathrm{a}$ & $\mathrm{n} / \mathrm{a}$ \\
\hline Sample 18 & Swab & 28.9 & $\checkmark$ & $\checkmark$ & Untypable & CVA6 & $\mathrm{n} / \mathrm{a}$ & $\mathrm{n} / \mathrm{a}$ \\
\hline Sample 19 & Skin Swab & 28.6 & $\checkmark$ & $\checkmark$ & Untypable & CVA6 & $\mathrm{n} / \mathrm{a}$ & $\mathrm{n} / \mathrm{a}$ \\
\hline Sample 20 & STHR & 30.75 & $\checkmark$ & $\checkmark$ & Untypable & CVB1 & $\mathrm{n} / \mathrm{a}$ & $\mathrm{n} / \mathrm{a}$ \\
\hline Sample 21 & CSF & 38.27 & $\checkmark$ & $\checkmark$ & Untypable & E5 & $\mathrm{n} / \mathrm{a}$ & $\mathrm{n} / \mathrm{a}$ \\
\hline Sample 22 & CSF & 33.81 & $\checkmark$ & $\checkmark$ & Untypable & CVB3 & $\mathrm{n} / \mathrm{a}$ & $\mathrm{n} / \mathrm{a}$ \\
\hline Sample 23 & CSF & 33.78 & $\checkmark$ & $\checkmark$ & Untypable & E25 & $\mathrm{n} / \mathrm{a}$ & $\mathrm{n} / \mathrm{a}$ \\
\hline Sample 24 & $\mathrm{CSF}$ & 32.78 & $\checkmark$ & $\checkmark$ & Untypable & CVB3 & $\mathrm{n} / \mathrm{a}$ & $\mathrm{n} / \mathrm{a}$ \\
\hline Sample 25 & STHR & $13^{*}$ & $\checkmark$ & $\checkmark$ & Untypable & EV-A71 & $\mathrm{n} / \mathrm{a}$ & $\mathrm{n} / \mathrm{a}$ \\
\hline Sample 26 & $\mathrm{CSF}$ & $44^{*}$ & $\checkmark$ & $\checkmark$ & Untypable & E5 & $\mathrm{n} / \mathrm{a}$ & $\mathrm{n} / \mathrm{a}$ \\
\hline Sample 27 & CSF & $34^{*}$ & $\checkmark$ & $\checkmark$ & Untypable & E5 & $\mathrm{n} / \mathrm{a}$ & $\mathrm{n} / \mathrm{a}$ \\
\hline Sample 28 & CSF & $584^{*}$ & $\checkmark$ & $\checkmark$ & Untypable & E30 & $\mathrm{n} / \mathrm{a}$ & $\mathrm{n} / \mathrm{a}$ \\
\hline
\end{tabular}



(copies/ $\mu \mathrm{l}$ ) or Ct values (cycle threshold) and typing data received from the NRL for each specimen is shown for each sample. E, Echovirus; CVB, Coxsackievirus B; CVA, Coxsackievirus A; EV-A71, Enterovirus 71. NPA, nasopharyngeal aspirate; SWAB, swab from undefined site; STHR, swab from throat; CSF, cerebrospinal fluid; NRL, national reference laboratory; RT snPCR, reverse transcriptase semi-nested polymerase chain reaction. Enteroviral sequences located on Genbank under accession numbers MT614252-MT614274. 


\section{Discussion}

148 We observed a significant ( $p$ 0.0028) rise in untypable EVs from clinical specimens processed by the main EV typing and epidemiological data collection service in England so re-evaluated available residual sample TNA extracts by an alternative methodology recommended by the WHO [8]. PCRbased typing assays of RNA viruses requires regular primer review to monitor genome changes that result from high rates of evolution and frequent recombination events, notably in some species of EV between structural and non-structural genes $[3,22,23]$. EV typing is further challenged by the extensive diversity of clinically relevant isolates, spanning 116 types across 4 species often sampled in specimens with low viral load [24]. The current assay utilised by the English NRL employs speciesspecific primers to amplify the $\mathrm{N}$-terminus of the VP1 gene in EV species A-C only, overlooking EV-D entirely [13]. Sequencing of this region is the gold standard for EV typing [3] and species-specific primers can offer increased sensitivity compared to generic primers $[3,25,26]$. However, an in silico review identified multiple mismatches between the primers, designed in 2006 [13] and publicly available EV genomes in 2018. This concurs with an overall English NRL typing success rate of $69 \%$ between 2015 and 2017 [10] and 68\% in our cohort, highlighting not only the importance of designing sufficiently degenerate primers to accommodate naturally occurring variation across EV genomes, but also regular re-appraisal of primers for clinical diagnostics. If surveillance data are to be consistent and reliable, this accommodation should be within and across EV species without losing sensitivity and specificity [24]. in untypable isolates would not occur without also continued genetic drift or prevalence change in circulating EV isolates [23], such as the recent emergence of EV-CVA6 [10] of which we identified 3 previously untypeable isolates. Previous analyses of NRL typing results demonstrated complex EV epidemiology, with differing patterns of circulation and no evidence of any exclusively predominant EV strains $[10,11]$. Clinical audit and typing data presented here concurred with this finding, but EV- 

diverse range of EVs typed in this study shows a cross-species reduction in reference laboratory assay sensitivity.

Further coordination of surveillance data and genotyping methods from laboratories in the

UK, Europe and beyond would undoubtedly strengthen confidence in understanding of trends in enteroviral epidemiology $[3,10]$. Notably, surveillance centres identified a rise in cases of the highly pathogenic strains EV-A71 and EV-D68 across Europe and North America in recent years [27, 28] but EV-D68 has been missed by other molecular assays [29] and EV-D species are not targeted by the NRL assay [13] necessitating the implementation of an additional EV-D68 specific assay in England [30]. The current English NRL protocol therefore requires multiple PCR reactions to be performed per specimen, increasing cost, and potentially also processing time and risk of contamination, and may be unsuitable for low volume, low viral load, or non-repeatable samples, such as CSF, which is critical for diagnosing viral meningitis/meningoencephalitis, neonatal sepsis and acute flaccid paralysis/myelitis [3]. However, in principle, with suitably improved primers, this approach could offer a more sensitive typing assay by reducing the diversity of coverage required from each primer. The alternative RT-snPCR adopted in our study also targets conserved VP1 gene motifs, but using universal primers designed by the CODEHOP strategy based on conserved amino acid motifs within the target site, permitting broad target specificity and amplification of EV species A-D in one workflow $[16,31]$. By combining a conserved non-degenerate clamp at the primer $5^{\prime}$ end and a consensus degenerate core region at the $3^{\prime}$ end, these SNPCR primers continue to maintain broad specificity and primer template stability. 
including the highly pathogenic serotypes EV-C105 and EV-D68, can be achieved with this assay ([16] and supplementary file).

Previous investigations of UK EV typing data attributed untypable results to low viral loads and insufficient sample volume [11]. Samples of insufficient volume or failing initial NRL QC RT-PCR were not classified as 'untypable' in the study presented here. Analysis of untypable isolate viral loads showed EV was detected at Ct values 17.7 to 39.92 on the NUH diagnostic platforms between 2013-2017 (Table 2). No correlation was seen between these and cT values for isolates typed by the NRL, suggesting typing assay success is not proportional to viral load. RNA quality and specimen degradation post transit is controlled through additional 5' UTR PCR [13] so specimen transit is unlikely to contribute to typing failure. The modified RT-snPCR assay successfully genotyped $82.1 \%$ (23/28) of re-evaluated samples, failing to amplify VP1 in five samples. However, four had RNA of poor quality, as determined by our QC PCR, or were of insufficient volume to repeat (Table 2), leaving only one of the 24 viable samples (Sample 11) without a newly determined typing result. Although sequencing of the $5^{\prime}$ UTR suggested an EV-A (EV-A71), interspecies recombination within $5^{\prime}$ UTR is possible and thus this result is inconclusive [23].

In conclusion, this study highlighted declining reliability of a NRL EV typing assay over time and a viable alternative assay, readily achievable by local hospital laboratories, was presented. Realtime sharing of surveillance data to improve control of poliovirus and non-poliovirus EV strains, is an important future direction of EV diagnostics $[3,10]$. Therefore, regular evaluation and improvement of regional and NRL EV molecular assays should be undertaken to ensure optimal coverage is achieved, although service demand, focus and the available resources can vary considerably at local and reference levels [10]. The ENPEN Network recently highlighted the variation in the quality of EV diagnostics (detection and typing) across Europe [24], but also presents a roadmap for international collaboration in to significantly progress EV diagnostics. Exponential increase in available reference sequence data generated by contemporary advances in unbiased metagenomics sequencing makes this target more achievable in the future. 


\section{References}

227 1. Bennett JE, Dolin R, Blaser MJ. Mandell, Douglas, and Bennett's Principles and Practice of

228 Infectious Diseases. 8th ed: Saunders; 201415 Oct. 2014.

$2292 . \quad$ Diaz-Decaro JD, Launer B, McKinnell JA, Singh R, Dutciuc TD, Green NM, et al. Bayesian evidence and epidemiological implications of environmental contamination from acute respiratory infection in long-term care facilities. Epidemiology and infection. 2018:1-7. Epub 2018/04/11. doi: 10.1017/s0950268818000729. PubMed PMID: 29633685.

3. Harvala H, Broberg E, Benschop K, Berginc N, Ladhani S, Susi P, et al. Recommendations for enterovirus diagnostics and characterisation within and beyond Europe. Journal of clinical virology : the official publication of the Pan American Society for Clinical Virology. 2018;101:11-7. Epub 2018/02/08. doi: 10.1016/j.jcv.2018.01.008. PubMed PMID: 29414181.

4. Muehlenbachs A, Bhatnagar J, Zaki SR. Tissue tropism, pathology and pathogenesis of enterovirus infection. The Journal of pathology. 2015;235(2):217-28. Epub 2014/09/12. doi: 10.1002/path.4438. PubMed PMID: 25211036.

5. Giombini E, Rueca M, Barberi W, lori AP, Castilletti C, Scognamiglio P, et al. Enterovirus D68Associated Acute Flaccid Myelitis in Immunocompromised Woman, Italy. Emerging infectious diseases. 2017;23(10):1690-3. Epub 2017/09/21. doi: 10.3201/eid2310.170792. PubMed PMID: 28930024; PubMed Central PMCID: PMCPMC5621549.

6. McKinney RE, Jr., Katz SL, Wilfert CM. Chronic enteroviral meningoencephalitis in agammaglobulinemic patients. Reviews of infectious diseases. 1987;9(2):334-56. Epub 1987/03/01. PubMed PMID: 3296100.

7. Modlin JF. Enterovirus and parechovirus infections: Clinical features, laboratory diagnosis, treatment, and prevention https://www.uptodate.com/contents/enterovirus-and-parechovirusinfections-clinical-features-laboratory-diagnosis-treatment-and-prevention: Wolters Kluver; 2018. 8. World Health Organisation. Enterovirus surveillance guidelines: Guidelines for enterovirus surveillance in support of the Polio Eradication Initiative.

http://www.euro.who.int/ data/assets/pdf file/0020/272810/EnterovirusSurveillanceGuidelines.p df: 2015.

9. Mahony JB, Petrich A, Smieja M. Molecular diagnosis of respiratory virus infections. Critical reviews in clinical laboratory sciences. 2011;48(5-6):217-49. Epub 2011/12/22. doi: 10.3109/10408363.2011.640976. PubMed PMID: 22185616.

10. Bubba L, Broberg EK, Jasir A, Simmonds P, Harvala H, Enterovirus study c. Circulation of nonpolio enteroviruses in $24 \mathrm{EU}$ and EEA countries between 2015 and 2017: a retrospective surveillance study. Lancet Infect Dis. 2019. Epub 2019/12/25. doi: 10.1016/S1473-3099(19)30566-3. PubMed PMID: 31870905.

11. Kadambari S, Bukasa A, Okike IO, Pebody R, Brown D, Gallimore C, et al. Enterovirus infections in England and Wales, 2000-2011: the impact of increased molecular diagnostics. Clinical microbiology and infection : the official publication of the European Society of Clinical Microbiology and Infectious Diseases. 2014;20(12):1289-96. Epub 2014/07/22. doi: 10.1111/1469-0691.12753. PubMed PMID: 25039903.

12. Oberste SM, Gerber SI. Enteroviruses and Parechoviruses: Echoviruses, Coxsackieviruses, and Others. 5 ed. Kaslow RA, editor. New York: Springer; 2014. 
13. Iturriza-Gomara M, Megson B, Gray J. Molecular detection and characterization of human enteroviruses directly from clinical samples using RT-PCR and DNA sequencing. Journal of medical virology. 2006;78(2):243-53. Epub 2005/12/24. doi: 10.1002/jmv.20533. PubMed PMID: 16372287. 14. Holmes CW, Koo SS, Osman H, Wilson S, Xerry J, Gallimore Cl, et al. Predominance of enterovirus $B$ and echovirus 30 as cause of viral meningitis in a UK population. Journal of clinical virology : the official publication of the Pan American Society for Clinical Virology. 2016;81:90-3. Epub 2016/07/02. doi: 10.1016/j.jcv.2016.06.007. PubMed PMID: 27367546.

15. Loens K, Bergs K, Ursi D, Goossens H, leven M. Evaluation of NucliSens easyMAG for automated nucleic acid extraction from various clinical specimens. Journal of clinical microbiology. 2007;45(2):421-5. Epub 2006/12/15. doi: 10.1128/jcm.00894-06. PubMed PMID: 17166966; PubMed Central PMCID: PMCPMC1829055.

16. Nix WA, Oberste MS, Pallansch MA. Sensitive, seminested PCR amplification of VP1 sequences for direct identification of all enterovirus serotypes from original clinical specimens. Journal of clinical microbiology. 2006;44(8):2698-704. Epub 2006/08/08. doi: 10.1128/jcm.00542-06. PubMed PMID: 16891480; PubMed Central PMCID: PMCPMC1594621.

17. Nix WA, Berger MM, Oberste MS, Brooks BR, McKenna-Yasek DM, Brown RH, Jr., et al. Failure to detect enterovirus in the spinal cord of ALS patients using a sensitive RT-PCR method. Neurology. 2004;62(8):1372-7. Epub 2004/04/28. PubMed PMID: 15111676.

18. Oberste MS, Maher K, Flemister MR, Marchetti G, Kilpatrick DR, Pallansch MA. Comparison of classic and molecular approaches for the identification of untypeable enteroviruses. Journal of clinical microbiology. 2000;38(3):1170-4. Epub 2000/03/04. PubMed PMID: 10699015; PubMed Central PMCID: PMCPMC86366.

19. Dierssen U, Rehren F, Henke-Gendo C, Harste G, Heim A. Rapid routine detection of enterovirus RNA in cerebrospinal fluid by a one-step real-time RT-PCR assay. Journal of clinical virology : the official publication of the Pan American Society for Clinical Virology. 2008;42(1):58-64. Epub 2008/01/01. doi: 10.1016/j.jcv.2007.11.016. PubMed PMID: 18164234.

20. Altschul SF, Gish W, Miller W, Myers EW, Lipman DJ. Basic local alignment search tool. Journal of molecular biology. 1990;215(3):403-10. Epub 1990/10/05. doi: 10.1016/s00222836(05)80360-2. PubMed PMID: 2231712.

21. Kroneman AV, H.; Deforche, K.; Avoort, H.V.; Penaranda, S.; Oberste, M.S.; Vinje, J. . An automated genotyping tool for enteroviruses and noroviruses. Journal of clinical virology : the official publication of the Pan American Society for Clinical Virology. 2011;51(2):121-5.

22. Leitch EC, Harvala H, Robertson I, Ubillos I, Templeton K, Simmonds P. Direct identification of human enterovirus serotypes in cerebrospinal fluid by amplification and sequencing of the VP1 region. Journal of clinical virology : the official publication of the Pan American Society for Clinical Virology. 2009;44(2):119-24. Epub 2009/01/13. doi: 10.1016/j.jcv.2008.11.015. PubMed PMID: 19135410.

23. Simmonds $P$, Welch J. Frequency and dynamics of recombination within different species of human enteroviruses. J Virol. 2006;80(1):483-93. Epub 2005/12/15. doi: 10.1128/JVI.80.1.483493.2006. PubMed PMID: 16352572; PubMed Central PMCID: PMCPMC1317522.

24. Hayes A, Nguyen D, Andersson M, Anton A, Bailly JL, Beard S, et al. A European multicentre evaluation of detection and typing methods for human enteroviruses and parechoviruses using RNA transcripts. Journal of medical virology. 2019. Epub 2019/12/29. doi: 10.1002/jmv.25659. PubMed PMID: 31883139.

25. Nasri D, Bouslama L, Omar S, Saoudin H, Bourlet T, Aouni M, et al. Typing of human enterovirus by partial sequencing of VP2. Journal of clinical microbiology. 2007;45(8):2370-9. Epub 2007/06/01. doi: 10.1128/jcm.00093-07. PubMed PMID: 17537940; PubMed Central PMCID: PMCPMC1951248.

26. Mirand A, le Sage FV, Pereira B, Cohen R, Levy C, Archimbaud C, et al. Ambulatory Pediatric Surveillance of Hand, Foot and Mouth Disease as Signal of an Outbreak of Coxsackievirus A6 Infections, France, 2014-2015. Emerging infectious diseases. 2016;22(11):1884-93. Epub 
2016/10/22. doi: 10.3201/eid2211.160590. PubMed PMID: 27767012; PubMed Central PMCID:

320 PMCPMC5088007.

321 27. Holm-Hansen CC, Midgley SE, Fischer TK. Global emergence of enterovirus D68: a systematic review. Lancet Infect Dis. 2016;16(5):e64-e75. Epub 2016/03/02. doi: 10.1016/S1473-

323 3099(15)00543-5. PubMed PMID: 26929196.

324 28. Messacar K, Spence-Davizon E, Osborne C, Press C, Schreiner TL, Martin J, et al. Clinical characteristics of enterovirus A71 neurological disease during an outbreak in children in Colorado, USA, in 2018: an observational cohort study. Lancet Infect Dis. 2020;20(2):230-9. Epub 2019/12/21. doi: 10.1016/S1473-3099(19)30632-2. PubMed PMID: 31859216. 29. Jaramillo-Gutierrez G, Benschop KS, Claas EC, de Jong AS, van Loon AM, Pas SD, et al. September through October 2010 multi-centre study in the Netherlands examining laboratory ability to detect enterovirus 68 , an emerging respiratory pathogen. Journal of virological methods. 2013;190(1-2):53-62. Epub 2013/03/06. doi: 10.1016/j.jviromet.2013.02.010. PubMed PMID: 23458694 . 30. The United Kingdom Acute Flaccid Paralysis Afp Task F. An increase in reports of acute flaccid paralysis (AFP) in the United Kingdom, 1 January 2018-21 January 2019: early findings. Euro Surveill. 2019;24(6). Epub 2019/02/14. doi: 10.2807/1560-7917.ES.2019.24.6.1900093. PubMed PMID: 30755296; PubMed Central PMCID: PMCPMC6373064. characterization of viral genomes. Virology journal. 2005;2:20. Epub 2005/03/17. doi: 10.1186/1743422x-2-20. PubMed PMID: 15769292; PubMed Central PMCID: PMCPMC1079958. 